\title{
PROCESS IMPROVEMENT AND ICTS IN AUSTRALIAN SMES: A SELECTION AND IMPLEMENTATION FRAMEWORK
}

\section{Susu Nousala' ${ }^{1}$ Panayiotis Ifandoudas ${ }^{2}$, Milé Terziovski ${ }^{3}$ and Ross Chapman ${ }^{2}$}

${ }^{1}$ Spatial Information Architecture Laboratory (SIAL), School of Architecture and Design, RMIT. Susu.nousala@rmit.edu.au T: 61399253524 F: 61399253460 \{Contact Author\}

${ }^{2}$ Centre for Industry and Innovation Studies (CInIS) (incorporating the EACC-NSW), University of Western Sydney

r.chapman@uws.edu.au T: 61246203245 F: 61246203791

${ }^{3}$ Centre for Global Innovation Management, (incorporating the EACC-VIC), The University of Melbourne: milet@unimelb.edu.au, T: 61383447868 F: 61383443714 


\title{
PROCESS IMPROVEMENT AND ICTS IN AUSTRALIAN SMES: A SELECTION AND IMPLEMENTATION FRAMEWORK
}

\begin{abstract}
This paper describes the development, modification and testing of a tool designed to assist small firms in making more appropriate decisions regarding Information and Communication Technology (ICT) selection and implementation. Using a combination of quantitative and qualitative methods, a number of possible tools were initially developed to support firm-based self-diagnostic exercises. Research outcomes from a joint European-Australian research project were regionalized for Australian conditions through collaborative product development with a number of Australian SME manufacturing firms. This paper reports on the pilot implementations and the outcomes achieved with these Australian SMEs. These implementations have shown successful outcomes for the trial SME participants and have led to the creation of an on-line self-assessment tool to allow wider access by interested SMEs.
\end{abstract}

Keywords

Process improvement; ICTs; SMEs; Manufacturing; Case Studies; Diagnostic

\section{Introduction}

The aim of this paper is to report the Australian experience of the Cost-Worth project. The CostWorth project investigated methods which supported sound decision making with regard to Information and Communication Technology (ICT) selection and implementation. Sound business decisions in ICT implementation influenced and accelerated business process improvements that were attempting to respond to pressures of global competition, e-commerce and increasing customer sophistication. The project involved the modification and implementation of the Cost-Worth toolbox, namely the Cost-Worth Questionnaire (CW Questionnaire) and the Australian BEP2 methodology, to assist SMEs in the selection and implementation of ICT for the purpose of process improvement and, competitive advantage. The project involved the Australian SME partners to systematically review their processes and prioritise areas for ICT improvements. The Cost-Worth methodology was pilot tested in six Australian SMEs with the results supporting the view that through the use of appropriate guidelines, SMEs can increase their ability to successfully incorporate ICT into their business processes.

Many authors have provided definitions for ICT. We have followed that of Wilson (2003) as it clearly describes the integration of hardware and software into a functioning application with specific usage. "Concerning ICTs many definitions abound...I have written that ICT is merely a delivery system for 'content', albeit a system with two-way interactivity. ICT consists of both hardware (delivery) mechanisms and software (usage) capabilities. What is new is the integration capability in ICT by which delivery tools and content are merged into a seamless system" (Wilson 2003, p17).

What is becoming increasingly important in the business sector is the implementation of ICTs to assist in improving the responsiveness of a firm to market, environmental or technological developments. Brown and Bessant (2003) describe today's manufacturing environment as a new competitive landscape that is characterised by ongoing and heightened levels of competition that 
demands flexibility, increased delivery speed and innovation. The operations management literature generally supports this view, for example, Huang and Mak (1999) argued that the manufacturing environment is characterised by rapid changes, with these changes ultimately reflected in very different products and manufacturing processes. Furthermore, Stalk (1998) identified response time as the single most important criteria for achieving a competitive advantage in manufacturing companies.

The benefits of incorporating ICTs to assist in the rapid responsiveness of a business have been identified as: more effective and efficient information flows; assisting in value-adding improvements for current processes; greater access to efficiency enhancing innovations throughout the value chain (Productivity Commission, 2004); and the ability to access world markets through e-commerce (Kinder, 2002). As discussed in the literature, (Hammer 1990; Kinder 2002; Hall 1993; Fernandes et al 2001; Crowe et al 2002) implementation of ICT can be delivered in the form of a Business Process Reengineering (BPR) project. BPR has been a popular approach for improving the effectiveness and efficiency of processes (Hammer, 1990). However, the literature reports high failure rates of reengineering efforts, particularly in SMEs (Hall, 1993). Without the necessary guidelines and support a BPR project can deliver few benefits and even prove to be detrimental, as Fernandes, et al (2001) discovered with approximately 50-70 per cent of BPR exercises failing to achieve the intended results. Crowe et al (2002) put the figure at 80 per cent of projects either failing or suffering major problems. ICT implementation does not necessarily need to adopt a BPR approach.

ICT has been considered worth the risk, given the competitive pressures placed on business to keep pace with technology. For example, in Australia, the uptake of ICTs has increased dramatically towards the later part of the 90's and into the $21^{\text {st }}$ Century. Reports show that in 1993-94, 50 per cent of firms used computers with 30 per cent having internet access; by 2000-01 these figures had increased to 85 per cent and 70 per cent respectively (Productivity Commission, 2004).

The Cost-Worth project (“Coaching Support Tool to better identify Working process improvements Through introduction of intelligent manufacturing system solutions) was a multi-nation research and technology project with the principal aim of creating an innovative, application-oriented with a practicable software-based methodology to assist SMEs in the selection and implementation of ICT solutions. The Australian component of the Cost-Worth project commenced several months after the European development work had been completed. Appropriate funding in Australia was obtained under the International Science Linkage Program administered by the Australian Government's Department of Education Science and Training. The Australian team consisted of joint research partners from Victoria and NSW, along with several SME industry partners from these two states. In Victoria, the Euro-Australian Cooperation Centre (EACC-VIC) which was incorporated within the Centre for Global Innovation and Entrepreneurship at The University of Melbourne, and three key industry partners from Victoria agreed to participate: Autotek, SCS Plastics, and Jensen’s Foods. In NSW, the Euro-Australian Cooperation Centre (EACC-NSW) which was incorporated within the InCITe Research Group at The University of Western Sydney had three key SMEs partners from NSW who agreed to participate: AEM Australia, Broens Industries, and Stemar Electrical Products.

The Institute for Applied Systems Technology Bremen (ATB), based at The University of Bremen developed a generic methodology as part of a previous EU Funded Project (SMART SME Project). The methodology was the Best Enterprise Practice (BEP) Methodology. During the conceptualisation phase of the project it was decided by all partners to modify the BEP methodology so that a more specific, customised version of BEP could be used for the Cost-Worth Project. This gave rise to the Australian version called the BEP2 Methodology. 
The research reported herein has followed the sequence of actions as shown in Figure 1, and has used a combination of quantitative and qualitative techniques. The feedback loop shown in this diagram was important as this assisted the firms in undertaking their selected ICT implementations, and provided an action research perspective to the project. This paper is also structured roughly along the sequential stages shown in Figure 1.

[Take in Figure 1 about here]

\section{Background}

A gap exists in current literature regarding the area of ICT implementation for SMEs. The productivity Commission (2004) noted that large firms were earlier and stronger in their uptake of ICT than that of smaller firms and cited several reasons for this occurrence such as expected benefits, cost of equipment and the lack of financial strength to survive the risks of early adoption. Chapman et al (2000) cited that a lack of understanding of the available opportunities, a lack of understanding as to how to implement ICT, a shortage of available skills and the price of technology as major reasons why small firms struggled with ICT adoption. Furthermore, small businesses tended to be personally driven which resulted in the manager/owner's attitude towards technology significantly impacting on the uptake of ICTs, attitudes not common amongst larger firms (Culkin and Smith, 2000). One key issue that was common throughout the literature was that SMEs lack the necessary skills and resources to effectively implement and use ICTs (Culkin and Smith, 2000; Martin and Matlay, 2001). As SMEs lacked the necessary resources to successfully implement ICT in the same way as large businesses it was logical to assume that SMEs required a different approach to ICT implementation than that of large firms (Martin and Matlay, 2001). Lacono and Wigand (2005, p 211) note that whilst ICT had long been an "important theme" in the information field, individual SME firms may have had little ability to influence their industries. It was possible for SMEs to have some joint impact within their industries through aggregated effects or generic approaches (such as the Cost-Worth project offered, however, this would need further investigation) for example, performance effects, changes in employment, nature of work and use of tools could all impact on the industry subsequently effecting firms along the value chains.

Whilst SMEs were not scaled down versions of larger firms, Ketokivi (2006, p226) argued that flexibility and the contingencies either enabled or constrained the feasibility of certain manufacturing strategies and that these strategies needed to be incorporated into strategic and technological contingencies. Howard (2005, p 249) argued that ICTs provide the capability to create productive alliances that enabled a firm's engagement with the market in a more flexible manner; for example; adjusting to market preferences via the use of the Internet. SMEs trying to implement process innovation with IT based approaches needed to base these improvements on existing competencies and business objectives (Swanson and Wang 2005; Attewell 1992; Nelson and Winter 1982). SMEs were also indirectly supported or constrained by competencies within their industry (Winter 1987; Swanson and Wang 2005). Swanson and Wang discussed a firm’s success to innovate or improve with IT based approaches that hinged on "both its know-why for adoption and its knowhow for implementation and assimilation” (Swanson and Wang 2005, p 21). Swanson and Wang went on to say that timing of the firm's engagement with the innovation of processes was especially important. Hadjimanolis and Dickson (2000, p 62) also proposed timing as an issue, due to the special problems that SMEs face whilst selecting appropriate technologies. "The risks in responding to market and technological opportunities and selecting the appropriate actions at the right time 
(neither too early, nor too late) make innovation strategy a major challenge for their [SMEs] management”.

What was not clear from the literature was exactly what process SMEs should follow to successfully adopt ICTs within their business processes. Issues such as a reactive or proactive approach by the owner/manager to technology changes and management commitment and perception of benefits were cited as key issues for SMEs (Martin and Matlay, 2001). However, deciding upon which of the many and rapidly changing technologies available to adopt, (given the lack of resources) represented a significant problem for small business. As Martin and Matlay (2001) suggested small firms required clear external guidelines for evaluating ICT possibilities. Lee and Chuah (2001, p 688) stated that, "In order to ensure selection of the appropriate improvement strategy or approach, much time and effort is needed to understand the underlying concept, methodology and impact of each approach". Furthermore, they argued that the literature failed to provide adequate guidance on how to effectively follow these steps. Crowe et al (2002) posited that there existed a need to have a quantitative risk assessment tool to aid in business process projects to compensate for the high failure rate.

There has been much written about the links between business process redesign (or Business Process Re-engineering - BPR) and ICT implementation. Markus and Benjiman (1997) noted that IT and business process redesign are highly interdependent. Davenport and Short (1990) believed that IT and process redesign could 'transform the organisation to the degree that Taylorism once did' (p. 11 ), and they go on to argue that "IT and process redesign are natural partners, and with leadingedge practice have a recursive relationship....each is the key to the other" (p. 12). A predominant theme in all BPR literature has been the importance of using IT as an enabler and a tool to build new processes with, rather than build around (Hammer, 1990; Hammer and Champy 1993; Gunasekaran and Nath, 1997). Cole, (1994, p. 6) discussed the importance of information technology being the main supportive tool in building new processes. Davenport (1993) noted that the changes made to processes in a BPR program much more dramatic than any other performance improvement tool, "the risks of process innovation are at least proportional to the rewards" (Davenport, 1993, p. 15). While the links between ICT implementation and BPR have been noted, this research has been predominately situated within the ICT and SME process improvement literature.

Gunasekaran \& Nath (1997) elaborated on the successful implementation of ICTs in the form of intelligent manufacturing systems. Gunasekaran \& Nath (1997) discussed how companies usually need to satisfy three important goals to be effective; the first being, the approach taken from a process perspective, not a product-focused one. The second of these goals involved the integration of cross-functional activities. The third goal was concerned with achieving consistency between organisational goals and business plans. Intrinsically, IT was seen as integral to the system and a means by which performance for these manufacturing companies to improve.

\section{Multinational Cost-Worth Conceptual Framework}

\section{Project Overview and Conceptual Framework}

The international Cost-Worth team developed a conceptual framework (Figure 2). The framework captured three phases of the Cost-Worth methodology: Analysis and Conception, Selection and Specification; and Implementation. Input was sought from all partners in the project to ensure that content validity was assured, particularly in establishing a strong link between theory and practice. 
This was a critical phase in the project to ensure that the Cost-Worth methodology and the associated tools and techniques would have a practical relevance as conceptualised by the Cost-Worth partners.

\section{Analysis \& Conception Phase}

The Analysis phase is the 'first-cut' implementation plan for the solution related to the process to be re-engineered. This phase includes the analysis of the company's strategy, the identification of bottlenecks and any parts of the business process requiring reconfiguration, the identification of best solution and relevant techniques and required technologies that need to be combined with the related financial analysis. A support tool for this phase allowed for the definition of several possible scenarios, where one or more of the improvement opportunities were considered. The investment, operational costs and expected benefits were estimated for each scenario. These factors formed a basis for defining the final Implementation Concept. A rough implementation plan was also defined. By the end of the analysis phase the management of the company should have acquired the necessary information to decide on the implementation of a particular solution concept. One possible result of this phase was that the process team could conclude that no solution was worth implementing. In this case, the subsequent phases of the methodology would not be implemented. (San Martin et al., 2003)

[Take in Figure 2 about here]

\section{Selection and Specification Phase}

The primary objective of the second phase of the Cost-Worth toolbox was to produce the detailed specification of the process to be re-engineered and the technological solution to be implemented. A risk analysis was conducted and the implementation plan was fully developed. This phase also included the elaboration of a Request for Proposals and the selection of the best provider for the specified systems. These objectives were reached through the detailed specification of the solution to be implemented, the specification of requirements that needed to be fulfilled by the provider of the technology for the detailed implementation plan and a final analysis of the Return on the Investment. (San Martin et al., 2003)

\section{Implementation Phase}

The objective of this phase was to make sure that the chosen quality measurement requirements had been accomplished within the time schedule fixed. The Toolbox of methodologies also provided training material on how to apply the Cost-Worth methodology and on general concepts related to business reengineering processes. The training material focused on how to apply the methodology and to facilitate the future exploitation of the methodology by other potential users. (San Martin et al., 2003).

\section{Research Methodology}

The major difference between the Australian and European SMEs was size. European SMEs generally had a higher turnover, more employees and greater capital. This difference was the catalyst for the modification of the Cost-Worth toolbox into an Australian version. The two tools that were developed during the Australian project were the Cost-Worth Questionnaire (CW Questionnaire, see Appendix) and the Australian version of the BEP2 tool. The CW Questionnaire was designed along the lines of the Cost-Worth theoretical Framework (Figure 2). As well as identifying the scope of 
ICT needs and the overall BPR strategy of the organisation, the CW Questionnaire gathered information regarding the order handling process as set out in Figure 3. The BEP2 (Best Enterprise Practice-2) tool was designed as a quantitative self assessment tool that focused (in detail) on the five key processes of order management, design, materials management, production, and delivery management (Figure 3). The BEP2 tool was based on a series of rules relating to each process with the key managers being asked to rate the questions in terms of importance and implementation level. Rules that were marked as both important and not implemented were regarded as "weak points" and constitute the areas that were in need of ICT implementation.

As a result of the size difference between European and Australian SMEs, the tools and methodologies within the Cost-Worth toolbox were modified to suit the Australian setting. The CW questionnaire and the BEP2 tool were taken to one of the SMEs for a trial run to establish its strengths and weaknesses as well as highlighting any modifications that were needed. The main issues to come out of this trial were the length of the tool as well as the wording of the rules. The plan of action was to reduce the length of the tool and re-word certain rules for greater clarity. As a result the CW questionnaire was better able to capture and scope of organizational problems and the BEP2 tool was able to "drill down” into statistical specifics. The BEP2 which originally consisted of 585 rules was reduced to 241 rules. The modification did not reduce the effectiveness of the tool; it just reflected the relative size differences between European and Australian SMEs and as such the scope of analysis needed.

The CW Questionnaire and the BEP2 tool were used in combination, and were utilized as a two-part approach. This allowed for an analysis of the companies' "weak points", in alignment with the European approach. This two-part approach allowed the researchers to take a company "snap shot" using the CW Questionnaire with a follow-up of a more in-depth focus using the BEP2 tool. The combination of the questionnaire and BEP2 tool resulted in the collection of qualitative and quantitative data. This data was then analysed by the project managers with the outcomes discussed with the SMEs for the purpose of initiating an implement of a possible ICT solution.

[Take in Figure 3 about here]

\section{Company Profiles}

As previously discussed in the methodology section the following examines two of the Australian SME partners involved in the project in some detail and provides only a brief overview and outcome for the other four companies. The two companies considered in greater detail are Auto-Tek and AEM Australia. It should be noted that the firms considered in this research are not well-established e-commerce adopters. In terms of Azumah et al's (2005) classification scheme for SME e-commerce adoption, they would be either half-fusion or fusion organisations, that is they are using mostly traditional technologies to manage the business, although they may be developing Internet and network technologies to manage key aspects of their operations. This is a very typical situation for manufacturing SMEs interested in applying ICTs to improve their competitive situation.

\section{Auto-Tek}

Over the last 30 years Auto-Tek has been operating in both Sydney and Melbourne. The Sydney operation has focused on the service side of the company. The OEM (original equipment manufacturing) aspect of the company is based at the Melbourne operation. The company has a hierarchical structure, employing 6 staff in each city, and hiring other temporary staff as required. It 
is still managed and owned by the original family which began the business in Sydney. The main warehouse and project offices are in Melbourne through which they supply the local and global manufactures (Boeing, Bosch, Bristol-Myers Squibb, Cadbury Schweppes, Calsonic, Dano, Delphi, Denso, Ford, Fujitsu, General Motors, Kraft Foods, Siemens and Toyota). The company also has offices/representation in Italy, Germany and the United States.

The Melbourne end of the company is an OEM business experiencing rapid growth. The company's business operations are continuously reviewed and improved, as required by their customers. These reviews and improvements are carried out by various means such as surveys and statistical methods that meet the organisation's goals. The company's quality systems (outlined in the quality manual) meet the requirements of QS 9000 third edition. Auto-Tek supports suppliers who also meet the company's standards and can further promote continual improvement in quality standards and competitiveness through their suppliers and in-house employee participation at all levels. Company goals are driven by the implementation of responsible management strategies and programs, ensuring a culture of consistent quality which is maintained throughout all levels of the organisation. Specifically, the company supplies major motor vehicle companies with four different types of steering wheels and various foot pedals. The company also specialises in concept show vehicles.

\section{AEM Australia}

AEM Australia is a small manufacturing plant in the outskirts of Sydney. AEM Australia employs 40 staff spread evenly among the office and the production floor. The office staff cover the managerial roles of purchasing, sales, accounts and planning with the bulk of the office staff in an engineering role. There is a very flat organisational structure with little excess managerial resources. AEM Australia's main operations are in the power industry with an annual turnover of \$7 million. AEM Australia produces switchgear, mainly dis-connectors or air brake switches for the transmission and distribution markets. The corporate objective of AEM Australia is very straightforward and that is to manufacture and customise electrical switchgear for a profit. The managing director stresses that the company is not in business in order to excel in customer service or the development of quality products. He believes that excellence in these areas is a necessity to even begin to compete in the market place and that for a company to be successful it has to produce quality products and provide high levels of customer service and do these things at a profit. The introduction of the theory of constraints has had a significant effect on the company since its adoption. The introduction caused a major shift in all aspects of the business, in particular the company culture and production.

The most important potential outcome of the project for AEM was seen as increasing revenue or more importantly, throughput. It was clear from the outset that ICT solutions would play an enabling role at AEM Australia as opposed to a driver of the business. A particular area that AEM Australia wished to improve was its scheduling. The scheduling is performed via software called ST-Point, a finite scheduling programme. Any improvements resulting from an ICT solution needed to relate to bottom line improvements for AEM Australia to see any benefits for undertaking the project.

\section{Case Studies - Implementation, Results and Analysis}

\section{Auto-Tek}

The Cost-Worth Questionnaire was applied to Auto-Tek to achieve a qualitative assessment of the company as a whole as well as the order handling management processes. The company considered this "over-all" approach more useful than the more specific BEP2 tool. The Cost-Worth Questionnaire allowed Auto-Tek to assess over all performance, at the same time highlighting 
specific outcomes for future goal-setting. There were three main key thematic points that emerged from the Cost-Worth Questionnaire, these were crucial to the company's success: Speed; Quality, and Continuous improvement. Some weak points were also identified from the Cost-Worth Questionnaire:

- Time to comply with quality requirements and keep up with and complete required workloads.

- Identifying new market positions in OEM niche market space.

- The required speed at which identifying niches in OEM - which underpins product and technical life cycles- which leads to - getting to market.

- Large companies in OEM market use Auto-Tek to provide products faster; however, profit is being eroded by the time taken for quality systems to be kept up to date, and to satisfy compliancy requirements in order to be a reliable part of the quality shield.

- Quality systems are becoming a burden, which in turn, could become burdensome for the company - eroding the core capability of doing things faster.

The creation of a new business model emerged from the application and analysis of CW Questionnaire and BEP2 to AutoTek's process, resulting in several new key outcomes. A new flow chart system was designed and developed. Essentially, it was simplified and made "visual" which meant that images of key components and stages were now coordinated and combined to minimise process execution and confusion. This was achieved via a new electronic data integration system (EDI) between AutoTek and their major customer, Ford Australia. An up-grade of the company's accounting system was also integrated. This new process also meant changes to the standard operating procedures which related to stock and movement in the warehouse. These changes also supported the necessary transition from ISO 9000 quality systems to the Ford Australia Q1 Supplier Certification process.

\section{[Take in Figure 4 about here]}

The key weak points identified in the BEP2 analysis were supported by the findings of the initial CW Questionnaire that identified the following improvement issues for Auto-Tek:

- Employee's attitudes towards IT (both positive and negative) affected the successful implementation or development of any business process.

- Effective cross-departmental process optimisation (for example, with Ford) Relevant information exchange was critical so all levels received information (customer, sales, marketing, complaints). Access and retrieval underpin this process, with speed, quality and ability of information exchange, which is required to analyse the niche market opportunities, and therefore create new and future market positions.

- Simple Robust IT system. This underpinned the entire weak point discussion, in the case of AutoTek, a robust and visual ICT solution needed to be explored.

However, the first step was to change the hierarchy of the company into a flat structure through modifications to their business processes using the newly developed flow chart, in particular:

- warehousing and distribution - materials/components/product in-out/storage/stock control of non conforming products.

- manufacturing - planning for manufacturing

- $\quad$ performance measurements and continual improvements 
The combination of the CW Questionnaire and BEP2 also assisted Auto-Tek to identify its core capabilities:

- Quality in OEM niche market (Auto-Tek is a "quality shield” through its systems, that is, the company is carrying the responsibility for their customer’s quality).

- Continuous improvement in OEM niche market.

- Maintaining quality and continuous improvement whist "doing things faster", than Large OEM market players.

\section{AEM Australia Pty Ltd}

The CW Questionnaire was applied to AEM Australia in order to get a qualitative assessment of the order handling process. AEM Australia is an innovative company that has incorporated IT into the business for the purpose of improving the operational effectiveness of the company. The introduction of the theory of constraints and the adoption of Optimised Production Technology (STPoint) revolutionised the way that business was performed. The growth in the product base and entry into new markets required a different way of scheduling production and as such provided the potential for a BPR project involving ICT solutions. The weak points identified include the lack of a product cost information system by the sales department, the ability for customers to view order status online as well as the ability to monitor the delivery of products and customer satisfaction via IT. Included in these weak points was the lack of customer input for both new product design and current products. These findings were then correlated with the quantitative data gathered through the use of the BEP2 diagnostic tool.

The results of the BEP2 analysis are presented in Figure 4 and represent the optimal rules that were rated as weak points. The BEP2 analysis was conducted via a face-to-face interview at AEM Australia (as it was the site for the pilot test) and subsequent meetings discussing both the qualitative findings and the BEP2 analysis were undertaken. The BEP2 analysis was conducted just over one month after the CW questionnaire and within that time several changes took place at AEM Australia. Furthermore, certain weak points identified in both the CW questionnaire and the BEP2 analysis, prompted rapid responses from AEM Australia.

\section{[Take in Figure 5 about here]}

The Materials Management section identified three weak points in the carrying of inventory. On further consultation with AEM Australia it was discovered that an ICT solution had been implemented and was now in the process of refinement. A bar coding system had been put in place and the information was fed into the scheduling software. As a result of this implementation an inventory system now existed, all storage locations were systemised and were labelled with each having its own bar code. The Delivery Management sub process was addressed in the qualitative analysis with the scope of an ICT solution being limited. The optimised use of transport capacities related to the packaging of the products. An improvement in this area would involve negotiating alternative delivery configurations with customers as opposed to making delivery more efficient through the use of ICT.

The weak points identified in the qualitative analysis such as a product cost information system for sales and a scheduling system to handle the distribution products have been addressed by the company. A data base was being developed that would provide up-to-date information to the sales department regarding product cost, production capacity and estimated lead times. A scheduling system has been pilot tested and is currently being monitored for the production of distribution 
products. As a result of changes within the company and several other projects operating in parallel it was decided by the researchers and the managing director to focus on an area of the business that was identified as a possible weak point and to date had not been addressed.

The weak points identified in the design department represent an area where in ICT solution may be possible. The qualitative analysis finding that over the past two years, particularly in the transmission market, AEM Australia has changed its behaviour and stopped asking the customer to evaluate the product and suggest improvements is consistent with the BEP2 results. Rule 6.8.2 the planned assignment of development tasks suggests that design is not strategically driven by customer requirements as is optimal. The following rules received the highest rating in importance and a medium weighting in terms of implementation level:

- 6.5.1 Development phases include design for manufacturing.

- 6.5.2 The improvement of product producibility.

- 6.9.1 Integration of external experts in the design process.

- $\quad$ 6.5.3 Design for assembly.

- $\quad$ 6.10.1 Planning and proof of product performance.

The qualitative analysis identified the ability for customers to view order status online as well as the ability to monitor the delivery of products and customer satisfaction via IT as possible weak points. The combined analysis, as well as further consultation with the managing director, has identified the collection of customer information and the subsequent use of this information in the design of products as an area that would benefit from process redesign and improved ICT implementation. The following recommendations were put forward:

- Record Customer input via IT.

- Maintain a record of all customer enquiries in a data base.

- Incorporate this information in the design department.

A second phase of the BEP2 tool was implemented in which a summary of weak-points was gathered from middle and senior managers (Figure 6). This was done to provide a broader perspective to the processes of the business and to attain employee feedback before deciding on an ICT solution.

\section{[Take in Figure 6 about here]}

The outcomes of the weak-points gathered from middle and senior managers were discussed in detail with the managing director. Rules 3.7.2 Indication of binding and minimised delivery dates and 3.7.4 Efficient delivery have already been acted upon with the implementation of two new procedures to increase the accuracy of delivery date information as well as a change in the flow of information giving more responsibility for the sales assistant to become more proactive. A cultural change to supplier management has decreased the frequency of material shortages by employing a more proactive stance on supplier delivery date performance.

The priority focus on the weak point analysis was the information derived from customers. To date the only explicit information on customers was customer complaints. There is a great deal of implicit knowledge on customers that is not communicated throughout the company. The issue of setting up a customer database in the form of a contact management system accessible to everyone in the business was discussed. Several commercial contact management systems were tested to see which 
one was best suited to the existing network. The selected contact management system was subsequently implemented creating a greater information flow from customers.

\section{Demonstration of the Cost-Worth Questionnaire and BEP 2 tool}

Following the successful piloting of the CW Questionnaire and the BEP2 tool at AEM Australia and Auto-Tek, the research team in Australia decided to apply either the CW Questionnaire or the BEP2 tool or both to the remaining SME partners. The following section provides a multiple cross-case analysis of the data which lead to the conclusion and implications for SME managers.

\section{Jensen's Foods}

Jensen's Choice Foods is a privately-owned company with one director and one major shareholder. The occupational structure of Jensen's Choice Foods is food manufacturing and distribution.

The company started as the Garlic People Australia and were a one-product company operating at the back of a butcher shop crushing fresh garlic for the butchery trade. Within five years, Jensen's were the first to have their freshly-crushed garlic on supermarket shelves in Australia. Jensen's expanded their product range so as not be too concentrated on one particular product. The company spent several hundred thousand dollars to renovate the Huntingdale plant, which was formally a pharmaceutical company. Huntingdale (a suburb in Melbourne) became the first plant to be called Jensen’s Choice Foods.

Originally, when the company moved to Huntingdale it employed 22 staff. Now it has 35 permanent full-time staff including managers in sales, accounting and operations, engineers, food technologists, production and administrative staff. Over the years, Jensen's have acquired many brands and have developed into a company with capital value of \$5 million. Some of the brands include Jensen's Foods, Sun Valley Spices, Aunty Kath's and Harvest House. Jensen's Wet Spices range is particularly reputable and successful in all major supermarkets. The company provides manufacturing services for other food marketers/manufacturers such as Heinz, Kraft, GoodmanFielder. Approximately $20 \%$ of their business is off shore about $60 \%$ of their business is domestic with their own brands which leaves about 20\% that's co-packing for other players in the industry.

\section{Application of the Cost-Worth Questionnaire}

The Cost-Worth Questionnaire was used to check the status of Jensen's Foods key processes. Jensen's chose to reengineer and improve processes by looking at information they received from the shop floor. For instance, this approach identifies the bottlenecks of every process, which enables constant improvement. This process entailed looking at the costs and benefits of each process and identifying what is worth changing. The above process is a form of scenario planning sensitivity analysis and a "What-if?" analysis. The organisation will strive to eventually adopt another change process that will enable total local control of all technology.

IT played a role in the organisation's BPR program in line control and machine control which is all IT-driven. Management systems, which are used for planning and performance monitoring, are also IT-driven. IT is definitely an enabler. The CEO states "there is nothing here that we couldn't do without ICT, but it enables us to do things more efficiently". The biggest barrier was financing because of the company's strict financial justification requirements. It was imperative to raise the funds for implementing new processes, especially for a small company which has limited resources. Lack of resources was identified as a barrier to effective process redesign. However, Jensen's were 
able to use their networks to overcome this barrier. In addition, the organisation has 3 in-house fitters and electricians who are experts in building new technology. The change process impacted the organisation's customer service as it reduced costs, delivered products faster to the customers and enabled the organisation to be more competitive in their market.

\section{SCS Plastics}

SCS Plastics Pty Ltd was established in October 1985 as a family business, locating its operation in the country town of Shepparton in the state of Victoria. Over the past 5 years the company has experience $100 \%$ growth with its staff size changing rapidly. The staff numbers currently at approximately 50. The company's aim was to create an operation that specifically catered to the packaging needs of the south east region of Australia. SCS Plastics manufacture disposable packaging, (polyvinylchloride PVC, polyvinyl acetate PVA, Polystyrene etc) which covers almost all industries and sectors. The company produces a large range of products covering diverse markets; for example, confectionary, hardware, cosmetics, stationary, meat or fish products, dairy and bakery products.

SCS Plastics provides services from concept design, tooling design and construction, material and process testing, final volume manufacture, product and follow up support. The company operates from two manufacturing facilities, with the head quarters located in Shepparton and the second site in Silvan, Melbourne. Distributions operate from these facilities to service the broad range of clients.

\section{Application of the Cost-Worth Questionnaire}

An ERP (Enterprise Resource Planning) package by SAP (micro version) and the Cost-Worth Questionnaire were implemented at roughly the same time in SCS Plastics. Current (before SAP) issues identified from the Cost-Worth Questionnaire were:

- No formal mission statement

- growth of business $80-100 \%$ increase in the last five years

- Family business, no formal structure

- Communication - very informal, mostly face to face

- No formal meetings - administrative and technical issues resolved through continuous casual face to face communication

- No organisational map processes

- Documentation through QA manual, which is updated

- Very diverse market - products cover virtually all sectors

- Continued growth may depend on securing more innovative produce - niche market as opposed to "me too" products

- Formalising process redesign elements to support future organisational strategies

- Formal systems; eg costings, measurement methods, to support overall productivity gains - becoming more efficient - knowing how to measure it and relating the cause to the success.

- Viewing IT as an enabler, not as a hindrance, getting past the cultural IT block.

Application of the more quantitative BEP2 tool at SCS provided the identification of weak points as described in Figure 7. This information reinforced the qualitative feedback obtained from the CostWorth questionnaire and allowed an improved implementation of the proprietary ERP software in the organisation.

[Take in Figure 7 about here] 
A second application of the Cost-Worth questionnaire highlighted SAP's role in the business processes process. The following key points were identified:

- Formalising business process elements to support future organisational strategies

- Formal systems; e.g., costings, measurement methods, to support overall productivity gains - becoming more efficient - knowing how to measure it and relating the cause to the success.

The Cost-Worth Questionnaire played a key role in identifying performance gaps for this fastgrowing SME. The motivation to invest in a simplified version of SAP was emphasised through the 'weak point' analysis of the BEP2 tool and the potential consequences and high opportunity costs if an ICT strategy was not adopted. The results so far are very promising. The growth of SCS Plastics growth has continued unabated. The important issue that emerged for the firm was that their systems had to keep pace with their growth strategy; otherwise the company could easily stagnate and fall into the trap of "growing pains." As the General Manager of SCS put it: "Viewing IT as an enabler, not as a hindrance, helps to get us past the cultural IT block"

\section{Broens Industries}

Broens is a small to medium enterprise situated in The Western Sydney region. It currently employs a little over one hundred people and is turning over \$16 million per annum. Broens' corporate objective is to supply quality products to the world and is heavily focused on the bottom line. In 2002 the acquisition of Kirby (a much larger company) caused a shift in the corporate objectives as Kirby's corporate strategy had to be taken into consideration. Kirby was very much a customerfocused global entity and this was incorporated into Broens' corporate goals. The markets that Broens operates in are very cyclical and as such the corporate objectives of Broens is profitability and sustainability with the driving force being product diversification. Broens has three distinct markets with a broad range of products within these markets. Broens is best described as a high tech manufacturer of products for mainly the automotive, aerospace and white goods industries, but it has diversified into any area that requires high-tech manufacturing

\section{Application of the Cost-Worth Tools}

Two of the Cost-worth tools were used at Broens for the purpose of identifying areas of improvement. The tools were the Cost-Worth Questionnaire and the BEP2 tool. The key issue to come from the testing of the tools was that the BEP2 analysis provided quantitative evidence to support the anecdotal belief that cross departmental communication was a weak point. Cross departmental communication is needed to overcome capacity constraints caused by three different departments all competing for same manufacturing resources. The solution to this problem is in adapting the newly-acquired ERP system to improve the communication lines between departments. Currently there is a team working on the scheduling and reporting capabilities of the software, and this is expected to provide efficient information to all departments as to the availability of resources. This same process is expected to provide information regarding order status. To date there is no tool to look at work in process and as such the monitoring of an order's status is difficult. All five weak points identified in the BEP2 analysis were seen to stem from the same problem of communication. The process of improving the communication is already in progress with the recommendation for a more extensive process redesign project to continue on this path. 


\section{Stemar}

Stemar is a small manufacturing plant with a long history of supplying equipment to large power supply authorities. The Stemar workforce consists of twenty-eight employees with five office staff and the remainder on the shop floor. Stemar has an annual turnover of \$4.1 million and competes in the field of electrical sensing devices specifically for voltage and current sensing with its major niche market being that of instrument transformers. Stemar also manufactures distribution equipment for underground electricity, although this makes up only $15 \%$ of their sales. Given the size of the business, Stemar has a very flat organisational structure with only two steps separating the general manager and the shop floor. Within this flat structure the main mode of organisational communication is verbal, although Stemar is quite advanced when it comes to IT. Stemar has implemented and ERP system, M1, that has the potential to cover every aspect of the business. However, the implementation and use of the ERP system was not being used in key areas such as capacity planning and scheduling.

Stemar viewed the BEP2 tool as an accurate identifier of their problems and acted on the weak points identified. The tool identified capacity and scheduling as the key areas of improvement. The company began by completely changing the layout of the factory to allow for an even flow. They changed their raw material process from dumping work once a week to feeding the factory on a daily basis, and they built a second test room (the capacity constraint) and placed and dedicated the testing facilities along the new production line. They have successfully modified the use of their ERP system to schedule and monitor production and have put more importance in the bar coding system that is meant to track production. The result of this is that they have achieved a massive increase in delivery date performance, which was the primary goal of the project.

\section{Key Issues from Multiple Cross-case Analysis}

The key issues emerging from the six SMEs was that the improvement of overall quality, cost reduction, increased flexibility, and health and safety (e.g. removing repetitive strain injuries) relied on the ability to recognise ICT tools as enablers rather than as cost items. The incorporation of both strategic and technological contingencies into the approach (via the qualitative and quantitative method) also supported increased flexibility (Ketokivi 2006). Health and safety was one of the easiest processes to reengineer. It involved observing the processes and tasks performed by workers that are repetitive and appropriate to automate, and hence eliminating the need for human involvement. Most SMEs targeted more incremental changes and eliminated bottlenecks rather than embracing radical change as initially espoused by Hammer (1990). There are two key lessons learned for SMEs in Australia:

1. Process redesign and improvement through ICT implementation are possible and affordable by SMEs if they are selected based upon a careful consideration of strengths and weaknesses in key business processes, and then customised to fit their particular needs. Step change improvements were avoided by the six SMEs due to the high risk levels that have emerged from the literature.

2. Process re-engineering approached from an ICT tools perspective is much easier to customise than the traditional method originally proposed by the Hammer.

3. The CW Questionnaire proved valuable to those SMEs that were in the early phase of process improvement. These SMEs tended to be at the early phase of the growth curve. On 
4. The general perception from many SME managers is that ICT tools were expensive and that "we do not have the expertise in-house to keep up to date with the latest technological developments." The analysis and the results from this study show that SMEs can use ICTs as strong levers for improving their processes, irrespective of where the SME is on the growth curve.

\section{Implications for Managers}

The aim of this paper was to describe the development, modification and trial implementations of the Cost-Worth toolbox to suit the Australian environment for the purpose of aiding our target companies in their selection and implementation of ICT. The literature reports that the use of appropriate ICTs can lead to significant improvements in business processes; such improvements are becoming evermore critical to all business including SMEs. Several insights into the lower success rate of ICT uptake among SMEs were noted as a lack of appropriate skills and resources, cost of software, lack of financial stability, and a lack of understanding as to how to implement ICT. The testing of the Cost-Worth methodology addressed these issues with the implications for managers as follows. The tools were used to highlight specific areas for improvement and to prioritise ICT projects in order to overcome the problem of a lack of resources. Identifying the processes to improve and seeking external assistance in achieving these process can help reduce the cost of ICT implementation and overcome the skills shortage issue by incorporating external expertise. The issue of a lack of guidance for implementing ICT in SMEs that contributes to the confusion and fear with ICT is strongly addressed by the structured approach of the Cost-worth toolbox for evaluating ICT possibilities.

The main implication of our results for SME managers is that 'a one-size fits all' reengineering methodology does not work in every SME situation. The generic model developed was customised for each particular SME's needs. For example, one of the SMEs found the CW Questionnaire very useful because it enabled them to align their systems and processes with their major customer, Ford Australia. SME Managers have to be aware that an 'off-the-shelf' solution for reengineering their processes is often a complete waste of resources that could have been deployed more successfully elsewhere in the organisation. SME Managers also have to realise that ICT is a powerful tool that can be used as a lever not only by large companies with ample resources but also by growing SMEs to reach global markets that would not have been possible several years ago. By providing self assessment, on-line tools and methods, SMEs would have the opportunity to improve their manufacturing processes themselves at their own pace, without engaging expensive consultants. The Cost-Worth Toolbox also aimed to reduce the costs and risks of re-engineering business and working processes by making intelligent manufacturing systems solutions accessible to most traditional manufacturing SMEs.

\section{Conclusion}

The major objective of the Cost-Worth project in Australia was to provide participating SMEs a means of selecting and implementing appropriate ICT for the purpose of business process improvements. Based on our empirical research findings, we conclude that SMEs can obtain significant benefits in cost reduction, quality improvement and cycle time reduction through a 
systematic and customised approach to ICT and process re-engineering and improvement The CostWorth tools that were developed and tested by the European partners required modification for the use in the Australian setting. The tools needed to reflect the differences in size between European and Australian SMEs with management structure, employee skills and financial stability key differences. As a result a streamlined version of BEP2 was developed and tested in Australia. Further modifications have been made since these case studies that have produced three online tools for the purpose of assessing ICT implementation in SMEs. These tools can also apply to small European SMEs that found the original tools too complex. The results are encouraging for future Australian-European collaboration involving SMEs and the utilisation of on-line, intelligent manufacturing tools and techniques.

\section{Acknowledgements}

The authors would like to acknowledge the support of an Innovation Access Program Grant from the Australian Government Department of Education, Science and Technology (Project Number CG040128); plus the support of Melbourne University and the University of Western Sydney, and assistance from the international Intelligent Manufacturing Systems (IMS) network. Further the authors would like to thank the European project research partners and their respective institutions: CARSA, Madrid, Spain; the University of Patras, Greece; the Institute for Applied Systems Technology Bremen, Germany; the National University of Ireland, Galway, and ETH Swiss Federal Institute of Technology, Switzerland, all of whom contributed to the international project under a $5^{\text {th }}$ Framework Programme "Information Society Technologies” grant. 


\section{References}

ATTEWeLL, P., 1992, Technology Diffusion and Organizational Learning: The case of business computing. Organizational Science, 3 (1): 1-19.

Azumah, G., KoH, S. C. L. AND MaGUIRE, S., 2005, E-organisation and its future implication for SMEs, Production, Planning and Control, 16 (6), pp.555-562

BROWN, S. AND BESSANT, J., 2003, The manufacturing strategy-capabilities links in mass customisation and agile manufacturing - an exploratory study. International Journal of Operations and Production Management, 23 (7).

Chapman, P., JAmes-Moore, M., Szczygiel, M., AND Thompson, D., 2000, Building Internet Capabilities in SMEs, Logistics Information Management, 13 (6), pp. 353-360.

Cole, R., 1994, Reengineering the corporation: A review essay. Quality Management Journal 1 (4), 77-85.

Crowe, T., Fong, P. M., BAuman, T, A., AND ZAYAS-CASTRO, J. L., 2002, Quantitative risk level estimation of Business process reengineering efforts, Business Process Management Journal, 8 (5) pp490-511. MCB University Press.

CULKIN, N. AND SMITH, D., 2000, An emotional business: a guide to understanding the motivational small business decision takers, Qualitative Market Research: An International Journal, 3, (3), pp 145-157.

DAVENPORT, T.H. 1993, Process Innovation, Reengineering Work Through Information Technology, Harvard Business School Press, Boston, MA.

DAVENPORT, T.H. AND SHORT, J.E., 1990, The New Industrial Engineering: Information Technology and Business Process Redesign, Sloan Management Review, pp. 11-27 (Summer).

Fernandes, K. J., RAJA, V.H., AND Morely, M, 2001, A System Level Testing Modelling Mechanism in a Reengineering Environment, Journal of Conceptual Modelling, Feb 2001, Issue 18.

GunASEKARAN, A., NATH, B., 1997, The role of information technology in business project engineering. International Journal of Productions and Operations Management 16 (8), 5-28.

HADJimanolis, A., DicKson, K., 2000. Innovation Strategies of SMEs in Cyprus, a Small Developing Country. International Small Business Journal, 18.4 (July-Sept) p. 62.

HALL, L.W. 1993, Six Elements for implementing and Managing Change, Logistics Information Management, 6 (2), pp. 353-360.

HAMmer, M. 1990, Reengineering Work: Don't Automate, Obliterate, Harvard Business Review, July-August. pp. 104-112.

Hammer, M And Champy, J. 1993, Reengineering the Corporation, Harper Business, New York.

HOWARD, M., 2005, Collaboration and the '3DayCar': a study of automotive ICT adoption'. Journal of Information Technology, 20, 245-258.

HUANG, G.Q. AND MAK, K.L. 1999, Current practices of managing engineering changes in United Kingdom manufacturing industries. International Journal of Operations and Production Management, 19 (1): 21-37. 
IACONO, S. AND WIGAND, R.T. 2005. Information technology and industry change: view from an industry level of analysis. Journal of Information Technology 20, pp. 211-212.

KetOKIVI, M., 2006, Elaborating the Contingency Theory of Organizations: The Case of Manufacturing Flexibility Strategies. Production and Operations Management, 15, (2) Summer, pp. 215-228.

KINDER, T. 2002, Emerging e-commerce business models: an analysis of case studies from West Lothian, Scotland, European Journal of Innovation Management, 5 (3), pp 130-151.

LeE K T AND ChuAh K B, 2001, A SUPER Methodology for Business Process Improvement - An industrial Case Study in HK/PRC, International Journal of Operations and Production Management, 21, (5/6), pp 687-706.

MARKUS, L.M. AND BENJAMIN, R.I., 1997. The magic bullet theory in IT-enabled transformation. Sloan Management Review, 55-68.

Martin, L. M. And Matlay, H., 2001. Blanket Approaches to Small Firm Support: Some lessons from the DTI adoption ladder. Journal of Internet Research, Winter.

Nelson, R.R. AND WinTER, S.G. 1982, An evolutionary theory of economic change, Harvard University Press, Cambridge, Massachusetts.

NousAlA, S. H., 2006. Tacit Knowledge Networks and their Implementation in Complex Organizations. PhD Thesis, RMIT University

Productivity Commission 2004, ICT Use and Productivity: A Synthesis from Studies of Australian Firms, Commission Research Paper, Canberra.

StAlK, G., 1988. Time - The Next Source of competitive Advantage. Harvard Business Review, July/ August.

SWANSON, E. B., WANG, P., 2005. Knowing why and how to innovate with packaged business software. Journal of Information Technology. 20, pp20-31.

TALWAR, R. 1993. Business reengineering - a strategy-driven approach, Long Range Planning, 26 (6) pp.22-40.

WiLson, D., 2003. The Future of Comparative and International Education in a Globalised World. International Review of Education - Internationale Zeitschrift für Erziehungswissenschaft - Revue Internationale de l'Education 49(1-2): pp.15-33.

WINTER, S.G. 1987, Knowledge and competence as strategic assets, in TEECE, D.J. (Eds),The Competitive Challenge: Strategies for Industrial Innovation and Renewal, Harper \& Row, New York, NY, pp.159-84. 


\section{Appendix - Cost-Worth Questionnaire}

Note: The following is a text-only version of the web-based COST-WORTH (CW) questionnaire used in the Australian SMEs as part of the COSTWORTH project. The questions are replicated in full with the selection of "clickable" answers listed immediately after each question and separated by semi-colons. Each section and page included the instructions: Please select the appropriate answer to each question below (for some questions more than one answer may be allowed). Once completed, you need to submit your answers to get a display of the outcomes for the section. Your answers will be saved into the database after you click on the "Next" button within each section. The system will recall your answers, and this will allow you to complete the survey over more than one session.

\section{SECTION A}

\section{Best Practice in Process Reengineering in Australian Small to Medium Enterprises (SMEs)}

This section contains the following two subsections:

A.1 General and Cultural Organizational Questions

A.2 Marketing and Management

\section{A.1 General and Cultural Organizational Questions}

Q1. Does the Corporate objective/Mission statement of your company incorporate the words: continuous improvement, customer focus, and/or integrative/holistic approach?

Yes; No; To some extent

Q2. How many employees work at your company?

1 - 25; 26 - 50; 51 - 100; 101 - 250; More than 250

Q3. Where do the company's employees work?

All on one site; At different branches, but all in the same city; At different branches, in different cities, but all in the same country; At different branches, including cities in other countries.

Q4. Have any significant competitive events transpired in the previous 5 years?

Yes; No

Q5. Which of the following elements are imprinted in your company's culture?

Continuous improvement; Quality driven; Customer focus; Holistic approach; Innovativeness

Q6. What are the preferred modes of communication throughout the organization?

Face-to-face meetings; Written letters/memos ; Phone calls; E-mail messages; Video conferences; Intranet /

Knowledge repository / Portal.

Q7. How is information shared between groups or individuals when discussing administrative issues?

Face-to-face meetings; Written letters/memos ; Phone calls; E-mail messages; Video conferences; Intranet /

Knowledge repository / Portal.

Q8. How is information shared between groups or individuals when discussing technical issues?

Face-to-face meetings; Written letters/memos ; Phone calls; E-mail messages; Video conferences; Intranet /

Knowledge repository / Portal

Q9. $\quad$ Does your organization "map processes"?

Yes; No; To some extent

Q10. Does your organization formally manage tacit (i.e. non explicit) knowledge?

Yes; No; To some extent

\section{A.2 Marketing and Management}

Q11. What product line(s) does your company manufacture?

Food / Beverages / Tobacco; Textiles; Clothing / Footwear; Wood / Wood products / Furniture; Paper / Paper products / Printing \& Publishing; Chemicals / Petroleum / Coal products; Non-metallic mineral products; Basic metal 
products; Fabricated metal products; Transport equipment; Other machinery and equipment (including Electronics and Electrical); Other manufacturing not itemised above.

Q12. Which is the nature of your company's market?

Perfectly competitive market; Oligopolistic; Monopolistic; Monopolistic competition

Q13. Is growth in new areas expected?

Yes; No; Potentially

Q14. Is there any planned expansion into new markets?

Yes; No; Potentially

Q15. Is there a current need to develop strategies for increasing sales and/or improving your market share/space? Yes; No; Potentially

Q16. How many suppliers does your company have?

None; 1-3; 4-10; More than 10

Q17. Does your company customise products for your customers'/final users' requirements?

Yes; No; To some extent

Q18. Would product changes cause disruption to your company's value chain or production line?

Yes; No; To some extent

Q19. How does your company commercialise its new products?

Selling to retailers; Direct marketing / Sales reps ; Selling on your company's web site; Catalogue sales

Q20. Does your company have or need, or is currently developing strategies to reduce its logistics/delivery and warehousing times and costs?

Yes; No

Q21. Do you currently wish to optimise or better co-ordinate information and communications technology (ICT) solutions for your organization (e.g.: using computerized systems to improve organizational processes)?

Yes; No; To some extent

Q22. If so, which specific area(s) do you wish to improve?

Planning; Design; Materials / production management; Order management; Logistics / delivery management;

Sales / marketing; Customer management; Administration / other supporting services.

\section{SECTION B - Business Process Reengineering (BPR)}

Q23. Which of the following BPR strategy elements are present within your organization?

Incorporation of change management; Provision for organizational communication; Radical change is allowed; Prescribes clearly defined goals/targets; Provides a variety of 'tools' to be used throughout the process(es) as necessary; Plans for customer supplier input; Integrates Information Technology (IT); Is flexible enough to be tailored to the organizations needs.

Q24. Which of the following does your organization consider to be the most important objective of a business process re-engineering program?

Increasing revenue; Ensuring product quality; Improving customer service.

Q25. You envisage making more productivity gains (i.e.: becoming more efficient) by taking which of the following actions?

Streamlining processes; Introducing innovations; Introducing new technologies

Q26. Do you view IT as an 'enabler' or as a 'driver' of the BPR program?

Enabler; Driver 
Q27. Is there a plan in your organization for continuous improvement and further change in the next few years? Yes; No

\section{SECTION C - Order Management}

Q28. Please describe the level of order management process?

Efficient and effective process flow; Moderate process flow; Minimal process flow; Ad-hoc process flow

Q29. Is there IT based information exchange with customers?

Yes; No; To some extent

Q30. Is the explicit co-ordination and documentation of customer orders undertaken?

Yes; No; To some extent

Q31. Does the Sales department have an appropriate and efficient cost information system?

Yes; No; To some extent

\section{SECTION D - Design}

Q32. Do you have an effective product design processes in place?

Yes; No; To some extent

Q33. What forces trigger the design process?

Internal strategic innovation; Externally driven by customers; Or both

Q34. Is there a prompt provision of information by design?

Yes; No; To some extent

Q35. Is this information integrated with other departments?

Yes; No; To some extent

Q36. Is there an efficient use of IT for common developments with suppliers and/or customers?

Yes; No; To some extent

Q37. Does the design process re-use components or standard modules as far as possible?

Yes; No; To some extent

\section{SECTION E - Production Management}

Q38. Please describe the level of production planning process?

Efficient and effective process flow; Moderate process flow; Minimal process flow; Ad hoc process flow

Q39. Is there immediate provision of information by production?

Yes; No; To some extent

Q40. Are orders and capacity frequently monitored?

Yes; No; To some extent

Q41. Do you have "cycle teams"?

Yes; No; To some extent

\section{SECTION F - Materials Management}

Q42. Please describe the purchasing process?

Efficient and effective process flow; Moderate process flow; Minimal process flow; Ad hoc process flow 
Q43. Are there systems in place to ensure the minimization of warehousing and procurement costs?

Yes; No; To some extent

Q44. Is there efficient use of IT in purchasing and tracking materials?

Yes; No; To some extent

Q45. Is supplier performance monitored?

Yes; No; To some extent

Q46. How many suppliers does your company have?

None; 1-3; 4-10; More than 10

Q47. Is there an effective process for the selection of suppliers?

Yes; No; To some extent

\section{SECTION G - Delivery Management}

Q48. Please describe the delivery management system?

Efficient and effective process flow; Moderate process flow; Minimal process flow; Ad hoc process flow

Q49. Is information regarding delivery and customer satisfaction recorded via IT?

Yes; No; To some extent

Q50. Does routing and load planning exist to minimise delivery costs?

Yes; No; To some extent

\section{SECTION H - Performance Measurement}

Q51. Does your organization conduct any form of organizational performance measurements (e.g.: financial, customer capital, business processes, human capital)?

Yes; No; To some extent

Q52. Do you integrate the information in your strategy, formulation and implementation processes?

Yes; No; To some extent 


\section{FIGURES}

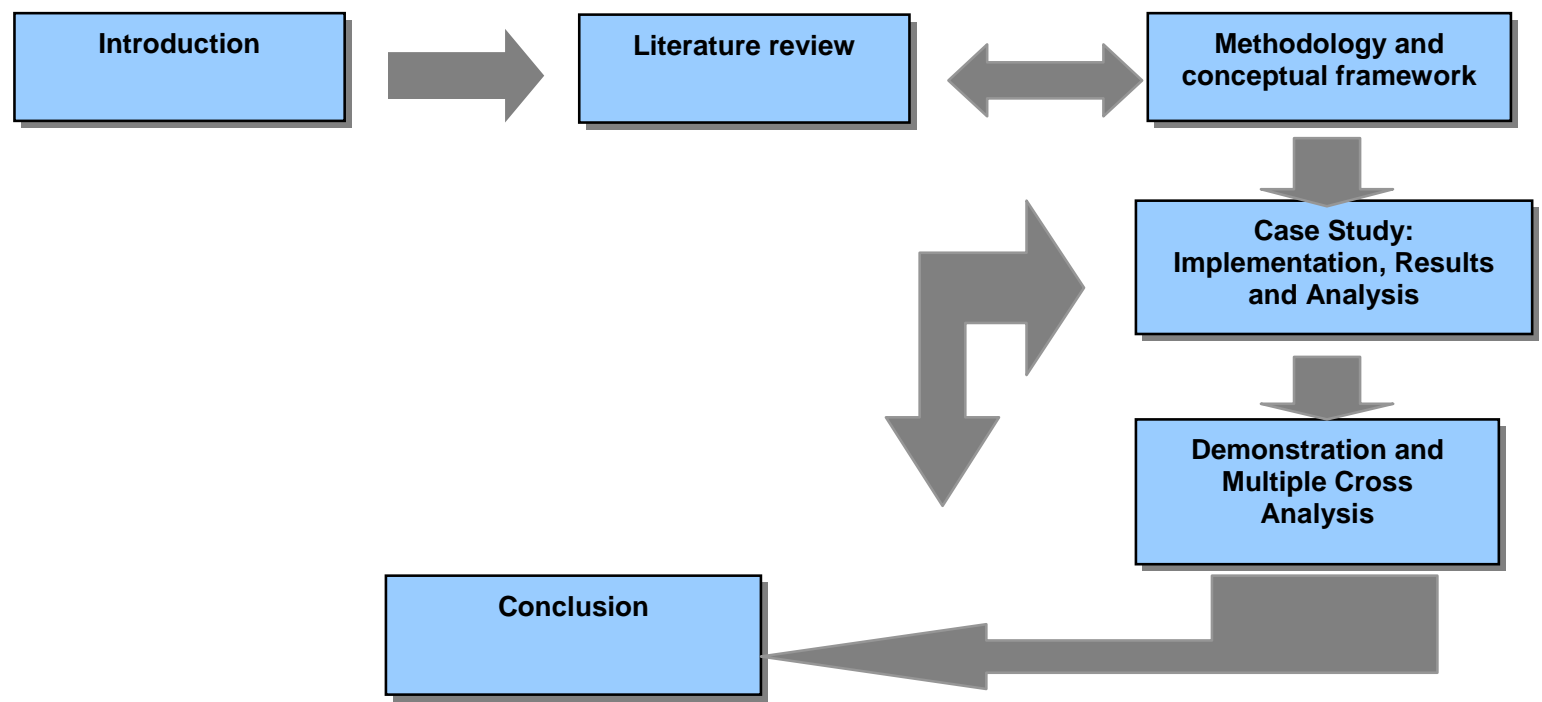

Figure 1 Project Outline (Nousala, 2006)

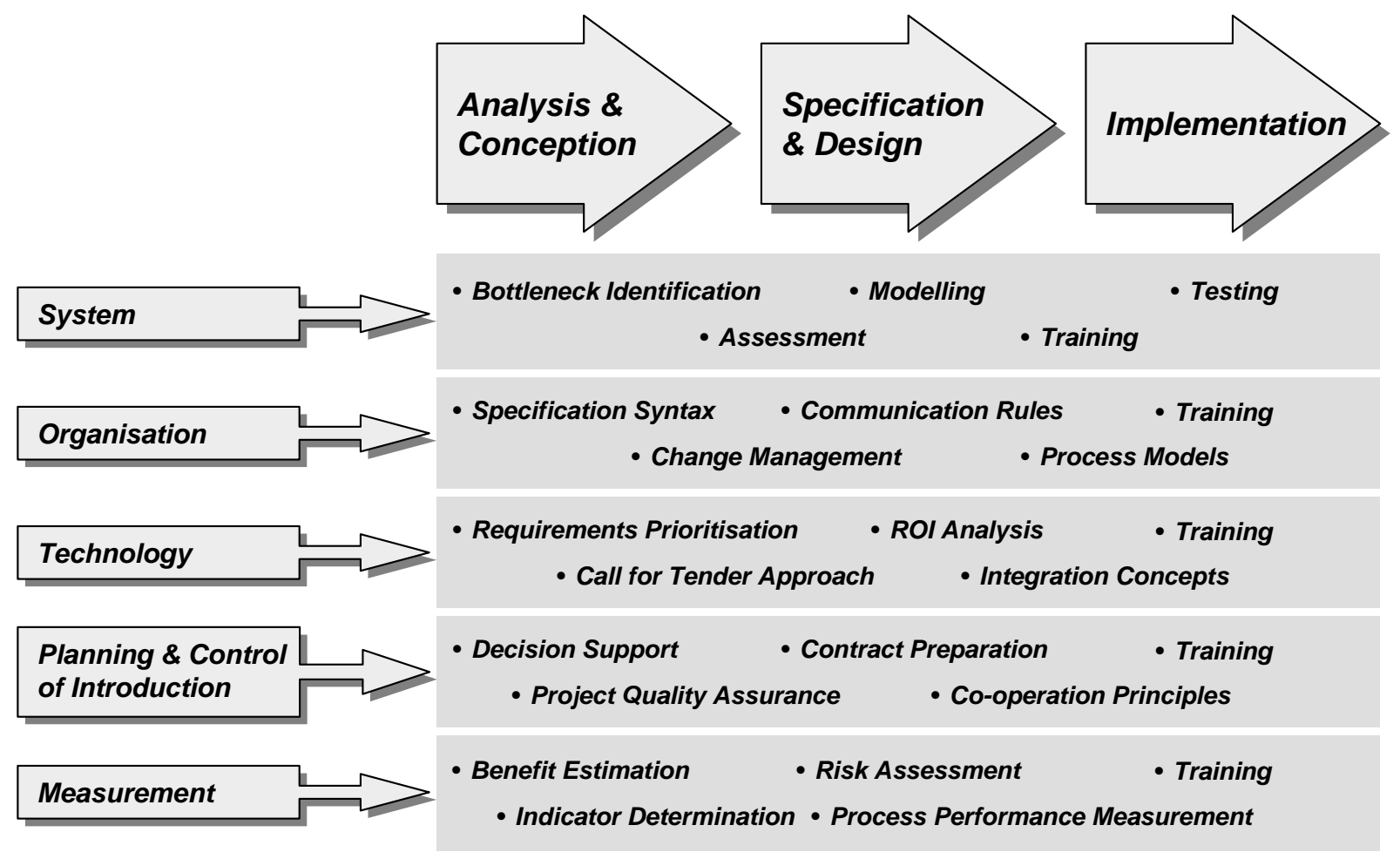

Figure 2 Conceptual Scheme on which the multinational Cost-Worth methodology is based

(Adapted from San Martin et al., 2003) 


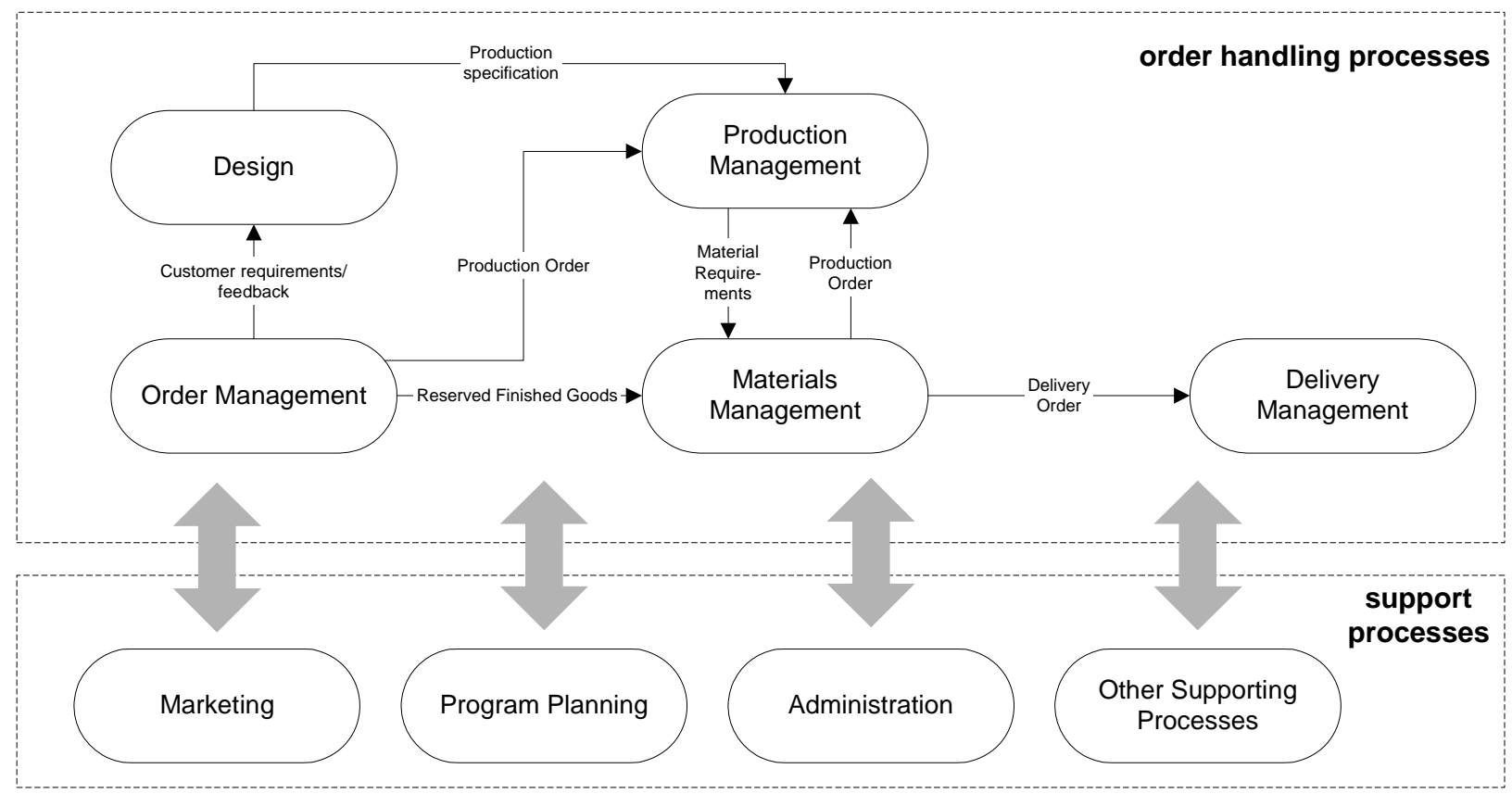

Figure 3 Order Handling Process

\begin{tabular}{|c|c|c|}
\hline Sub-Process & Activity & Role Name \\
\hline 1. Order Management & 1.1 Entire order mgt process & $\begin{array}{l}\text { 3.7.4 Efficient delivery } \\
\text { 3.7.5 Monitoring of order status } \\
\text { 3.8.2 IT based information exchange with } \\
\text { customers }\end{array}$ \\
\hline 2. Materials Management & $\begin{array}{l}2.1 \text { Entire material flow through } \\
\text { the business }\end{array}$ & 4.3.6 Monitoring of supplier’s performance \\
\hline 3. Design & $\begin{array}{l}5.1 \text { Conception, design and } \\
\text { elaboration }\end{array}$ & $\begin{array}{l}\text { 1.7.4 The consideration of employee attitude } \\
\text { towards IT } \\
\text { 2.3.1 Effective cross-departmental optim- } \\
\text { isation }\end{array}$ \\
\hline
\end{tabular}

Figure 4 Main Weak Points Identified using BEP2 Analysis at Auto-Tek

\begin{tabular}{|c|c|c|}
\hline Sub-Process & Activity & Rule Name \\
\hline \multirow{3}{*}{$\begin{array}{l}2 \text { Materials } \\
\text { Management }\end{array}$} & \multirow{3}{*}{$\begin{array}{l}2.1 \text { Entire material flow } \\
\text { through the business }\end{array}$} & 4.5.5 An actual inventory information system \\
\hline & & 4.5.6 The explicit and consistent notation and labelling of articles \\
\hline & & 4.6.3 Storage location of goods is distinct and known \\
\hline \multirow{3}{*}{$\begin{array}{l}3 \text { Delivery } \\
\text { Management }\end{array}$} & \multirow[t]{3}{*}{ 3.1 Delivery } & 1.3.1 The measurement of improvements to the delivery management process \\
\hline & & 3.7.4 The efficient delivery of products \\
\hline & & 4.4.1 The optimised use of transport capacities \\
\hline 5 Design & $\begin{array}{l}5.1 \text { Conception, design } \\
\text { and elaboration }\end{array}$ & 1.3.1 The measurement of design improvements \\
\hline
\end{tabular}

Figure 5 Weak Points Identified from Initial BEP2 Analysis at AEM 


\begin{tabular}{|c|c|c|}
\hline Sub-Process & Activity & Rule Name \\
\hline \multirow[t]{5}{*}{1 Order Management } & \multirow[t]{5}{*}{ 1.1 Entire order management process } & 3.4.3 Sufficient product information is readily accesible by customers \\
\hline & & 3.7.2 Indication of binding and minimised delivery dates \\
\hline & & 3.7.4 Efficient delivery \\
\hline & & 3.7.5 Monitoring of order status \\
\hline & & 3.8.2 IT based information exchange with customers \\
\hline \multirow{2}{*}{$\begin{array}{l}2 \text { Materials } \\
\text { Management }\end{array}$} & \multirow{2}{*}{$\begin{array}{l}2.1 \text { Entire material flow through the } \\
\text { business }\end{array}$} & 4.3.5 The forwarding of sales information to suppliers \\
\hline & & 4.3.6 The monitoring of supplier's performance \\
\hline \multirow{2}{*}{$\begin{array}{l}\text { 3Delivery } \\
\text { Management }\end{array}$} & \multirow[t]{2}{*}{ 3.1 Delivery } & 4.4.2 The efficient picking of products, e.g. at special picking places \\
\hline & & 4.5.7 JIT delivery by suppliers \\
\hline \multirow[t]{11}{*}{5 Design } & \multirow[t]{11}{*}{5.1 Conception, design and elaboration } & 1.7.4 The consideration of employees attitute towards IT \\
\hline & & 2.3.1 Effective cross-departmental process optimisation \\
\hline & & 2.3.3 The minimisation of "non-added-value" tasks \\
\hline & & 2.5.3 There is lear/efficient information administration \\
\hline & & 6.5.1 Development phases include design for manufacturing \\
\hline & & 6.5.7 Feedback on quality and needs, cause analysis for design problems \\
\hline & & 6.6.2 Customer oriented requirements analysis \\
\hline & & 6.7.2 Continuous information exchange between design and production \\
\hline & & 6.7.3 Integration of production experts in the design process \\
\hline & & 6.7.4 A complete set of production-relevant information is issued with design changes \\
\hline & & 6.11.1 Efficient acquisition of information by the development department \\
\hline
\end{tabular}

\section{Figure 6 Weak Points from Second Phase BEP2 Analysis at AEM}

\begin{tabular}{|c|c|c|}
\hline Sub-Process & Activity & Rule Name \\
\hline 1 Order Management & $\begin{array}{l}\text { 1.1 Entire order mgt } \\
\text { process }\end{array}$ & $\begin{array}{l}\text { 3.7.4 Efficient delivery } \\
\text { 3.7.5 Monitoring of order status } \\
\text { 3.8.2 IT based information exchange with customers }\end{array}$ \\
\hline 2 Materials Management & $\begin{array}{l}2.1 \text { Entire material flow } \\
\text { through the business }\end{array}$ & $\begin{array}{l}\text { 4.3.6 Monitoring of supplier’s performance } \\
\text { 4.5.5 An actual information inventory system }\end{array}$ \\
\hline 3 Delivery Management & 3.1 Delivery & 3.7.4 The efficient delivery of products \\
\hline 5 Design & $\begin{array}{l}\text { 5.1 Conception, design } \\
\text { and elaboration }\end{array}$ & $\begin{array}{l}\text { 1.7.4 The consideration of employees attitude to IT } \\
\text { 2.3.3 The minimization of "non-addded value" tasks } \\
\text { 2.5.3 There is lean/efficient information admin. } \\
\text { 6.7.2 Continuous information exchange between } \\
\text { design and production }\end{array}$ \\
\hline
\end{tabular}

\section{Figure 7 Weak Points Identified from BEP2 Analysis at SCS Plastics}

